Terbit online pada laman web jurnal: https://ejurnalunsam.id/index.php/jicom/

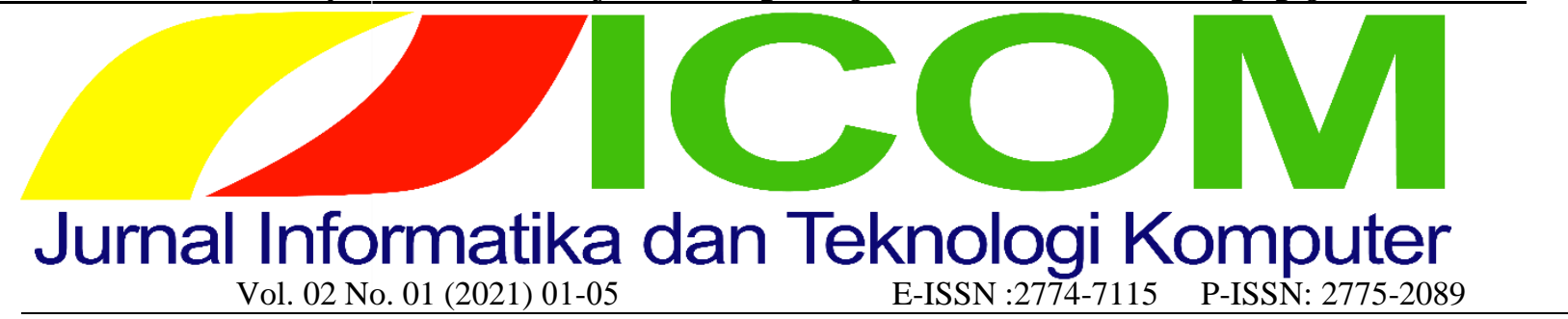

\title{
Kajian Daerah Rawan Kebakaran Kota Langsa Menggunakan Metode Weight Product (WP)
}

\author{
Heri Irawan ${ }^{1}$, Faiz Isma ${ }^{2}$, Irwansyah ${ }^{3}$ \\ ${ }^{1}$ Jurusan Teknik Industri, fakultas Teknik Universitas Samudra \\ ${ }^{2}$ JurusanTeknik Sipil, fakultas Teknik,Universitas Samudra \\ ${ }^{3}$ JurusanTeknik Sipil, fakultaş Teknik,Universitas Samudra \\ 1irawan84@unsam.ac.id*,2faizisma@unsam.ac.id, irwansyahradja@gmail.com
}

\begin{abstract}
This research was conducted to determine the Fire Prone Areas in Langsa City with the hope to realize the stability of regional development by minimizing potential losses that will be suffered and to attract investors to invest because there is a guarantee of security towards investment assets from fire hazards. By using the Weighting Product (WP) method to find out Fire-Prone Areas scattered in 5 Districts and 64 Gampongs in Langsa City based on predetermined criteria referring to Minister of Public Works Regulation No. 20 / PRT / M / 2009. From the results of the study using the Weighting Product (WP) method, it was found that there were 5 Gampong Subdistricts that were included in the prone category, 7 Gampong included in the rather vulnerable category and 1 in the relatively safe category. It can be said that this district must get serious attention considering the population density $(K P)$, fire history, and the distance from the water supply is large enough so that the index value is very high. While the East Langsa sub-district was classified as a fairly safe sub-district from 15 villages, there were 8 villages that were in the safe category, 7 villages were classified as somewhat safe, and none of them were classified as somewhat vulnerable, vulnerable and very vulnerable. This is because the area of east langsa is quite large with a population density that is not so dense and the range of water supply is close.
\end{abstract}

Keywords: Fire-Prone Areas, WP

\begin{abstract}
Abstrak
Penelitian ini dilakukan untuk mengetahui Daerah Rawan Kebakaran di Kota langsa dengan harapan untuk mewujudkan stabilitas pembangunan didaerah dengan cara meminimalisir potensi kerugian yang akan diderita dan untuk menarik investor agar berinvestasi karena adanya jaminan rasa aman terhadap aset investasi dari bahaya kebakaran. Dengan menggunakan metode Weighting Product (WP) untuk mengetahui Daerah Rawan Kebakaran yang tersebar di 5 Kecamatan dan 64 Gampong di Kota Langsa berdasarkan kriteria-kriteria yang telah ditentukan mengacu pada Peraturan Menteri Pekerjaan Umum No. 20/PRT/M/2009. Dari hasil penelitian menggunakan metode Weighting Product (WP) didapatkan bahwa Kecamatan Langsa Baro terdapat 5 Gampong yang masuk kategori rawan , 7 Gampong masuk kategori agak rawan dan 1 gampong yang masuk kategori agak aman. Hal ini bisa dikatatakan kecamatan ini harus mendapatkan perhatian serius mengingat variabel kepadatan penduduk (KP), histories kebakaran, dan jarak dengan pasokan air cukup besar sehingga nilai indeksnya sangat tinggi. Sedangkan kecamatan langsa timur masuk kategori kecamatan yang cukup aman dari 15 gampong yang ada 8 gampong masuk kategori aman, 7 Gampong masuk kategori agak aman dan tidak ada satupun yang masuk kategori agak rawan, rawan dan sangat rawan. Hal ini dikarenakan wilayah langsa timur yang cukup luas dengan kepadatan penduduk yang belum begitu padat dan jangkauan pasokan air dekat
\end{abstract}

\section{KatPendahoderah Rawan Kebakaran, WP.}

[8]Langsa adalah salah satu kota di provinsi Aceh yang sedang berkembang pesat pembangunannya. Hal ini sesuai dengan tujuan penataan ruang Kota Langsa adalah Mewujudkan Kota Langsa Sebagai Kota Pendidikan, Perdagangan, Jasa dan Agro Industri Yang Nyaman, Aman, Produktif, Berkelanjutan dan Islami.
[11] Dengan meningkatnya pembangunan diimbangi dengan peningkatan jumlah penduduk yang pesat mendorong perkembangan kawasan perkotaan dan kepadatan permukiman. Perkembangan tersebut secara tidak langsung menjadi penyebab terjadinya bencana kebakaran [9] Informasi mengenai daerah risiko kebakaran merupakan informasi yang sangat penting

Diterima Redaksi : 20-03-2021 | Selesai Revisi : 4-08-2021 | Diterbitkan Online : 07-04-2021 
dan diperlukan oleh fire manager atau pengambil dari [5] KEPMEN PU no. 11/KPTS/2000 untuk masingkeputusan di dalam kegiatan pengendalian kebakaran. masing variabel

Analisis dilakukan menggunakan metode Weight Product (WP). [5]Analisis daerah risiko bencana Tabel 1 Tingkat klasifikasi masing-masing variabel dan kebakaran dilakukan berdasarkan kriteria-kriteria yang penilaiannya KEPMEN PU no. 11/KPTS/2000. telah ditentukan mengacu pada Peraturan Menteri Pekerjaan Umum No. 20/PRT/M/2009. Sehingga mutlak harus diketahui daerah mana yang mempunyai resiko kebakaran yang tinggi sehingga kegiatan pengendalian difokuskan untuk wilayah-wilayah dengan resiko kebakaran yang lebih besar. [6] [7] Dijelaskan bahwa diperlukannya sebuah analisis resiko kebakaran untuk mewujudkan keselamatan dan keamanan terhadap bahaya kebakaran dan keamanan di perkotaan.

[7]Untuk menentukan tingkat kerawanan kebakaran, diperlukan data dan informasi dan lingkungan yang berpengaruh terhadap meluasnya kebakaran. Variabelvariabel terpilih dalam menentukan kerawanan kebakaran tersebut adalah kepadatan bangunan, tata letak bangunan, lebar jalan masuk, ukuran bangunan, kualitas atap bangunan dan aktivitas internal. Di samping itu penelitian juga mempertimbangkan [3]faktor penghambat menyebarnya kebakaran yang terjadi, yaitu jarak terhadap kantor pemadam kebakaran, jarak terhadap sungai dan ketersedian hidran

Penelitian sebelumnya [11] Paramater yang digunakan frekuensi kejadian, luas daerah kebakaran, jumlah bangunan permukiman terkena dampak, korban meninggal, dan lama waktu operasi pemadaman [1] 3 faktor resiko bencana yaitu faktor bahaya, faktor kerentanan dan faktor ketahanan. [2] Mengidentifikasi dan memetakan titik kebakaran hutan di kabupaten Kubu Raya berdasarkan analisis parameter kedalaman gambut,elevasi dan tutupan lahan. [4] Dengan metode Weight Product dapat memudahkan untuk menentukan daerah yang berpotensi kebakaran sesuai dengan bobot masing-masing kriteria yang sudah ditentukan dengan menghubungkan rating attribute, dimana rating tiap atribut harus dipangkatkan terlebih dahulu dengan atribut bobot yang bersangkutan.

\section{Metode Penelitian}

Penelitian ini dilakukan di 64 Gampong/Desa dari 5 Kecamatan yang ada di Kota Langsa Provinsi Nanggroe Aceh Darusalam. Data primer diambil dari instansi yang terkait seperti Kantor Badan Pusat statistik (BPS) dan Badan Penanggulangan Bencana Daerah (BPBD) Kota Langsa. Sedangkan Data Skunder diambil dari instansi yang terkait seperti Kantor Dinas Pekerjaan Umum dan Perumahan Rakyat (PUPR), Badan Perencanaan Pembanggunan Daerah (BAPPEDA) Kota Langsa. Analisis yang digunakan untuk menilai Kawasan Rawan Bencana Kebakaran menggunakan metode Weight Product (WP) dengan \% (persen) bobot sesuai ketentuan 


\begin{tabular}{|c|c|c|}
\hline Variabel & Bobot & Tingkat klasifikasi dan penilaiannya \\
\hline & & $\begin{array}{l}\text { apabila kepadatan penduduk < } \\
150 \text { jiwa/ ha }\end{array}$ \\
\hline \multirow{4}{*}{$\begin{array}{l}\text { Jangkauan } \\
\text { Pos PMK } \\
\text { (Respon } \\
\text { Time) }\end{array}$} & \multirow{4}{*}{$20 \%$} & $\begin{array}{ll}\text { a. } & \text { Nilai } 5 \text { = Diberikan untuk } \\
& \text { wilayah yang berada diiluar } \\
\text { radius pelayanan pos pemadam } \\
\text { kebakaran }(2.5 \mathrm{~km}) \text { hingga } \\
\text { perjalanan lebih dari } 15 \text { menit } \\
\text { atau diluar radius } 15 \mathrm{~km} \text { dan } \\
\text { dikategorikan sebagai } \\
\text { unprotected area } \\
\text { b. Nilai } 4=\text { Diberikan untuk } \\
\text { wilayah yang berada diiluar } \\
\text { radius pelayanan pos pemadam } \\
\text { kebakaran }(2.5 \mathrm{~km}) \text { dengan } \\
\text { waktu perjalanan antara } 10 \\
\text { hingga } 15 \text { menit atau dalam } \\
\text { radius } 10-15 \mathrm{~km}\end{array}$ \\
\hline & & $\begin{array}{l}\text { c. Nilai } 3=\text { Diberikan } \\
\text { untuk wilayah yang berada } \\
\text { diiluar radius pelayanan pos } \\
\text { pemadam kebakaran }(2.5 \mathrm{~km}) \\
\text { dengan waktu perjalanan antara } \\
5 \text { hingga } 10 \text { menit atau dalam } \\
\text { radius } 4.6-10 \mathrm{~km}\end{array}$ \\
\hline & & $\begin{array}{l}\text { d. } \\
\text { Nilai } 2=\text { Diberikan } \\
\text { untuk wilayah yang berada } \\
\text { diiluar radius pelayanan pos } \\
\text { pemadam kebakaran }(2.5 \mathrm{~km}) \\
\text { dengan waktu perjalanan antara } \\
\text { hingga } 5 \text { menit atau dalam } \\
\text { radius } 2.5-4.6 \mathrm{~km}\end{array}$ \\
\hline & & $\begin{array}{l}\text { e. Nilai } 1=\quad \text { Diberikan } \\
\text { untuk wilayah yang berada } \\
\text { didalam radius pelayanan pos } \\
\text { pemadam kebakaran terdekat } \\
\text { antara } 0-2.5 \mathrm{~km}\end{array}$ \\
\hline $\begin{array}{l}\text { Rasio } \\
\text { Jalan } \\
\text { Terhadap } \\
\text { Luas } \\
\text { Kawasan }\end{array}$ & $15 \%$ & $\begin{array}{ll}\text { a. } & \text { Nilai } 5=\text { Rasio jalan sangat } \\
\text { rendah. Yaitu luas jalan } \\
\text { perkotaan tidak melebihi angka } \\
1 \% \text { terhadap luas wilayah yang } \\
\text { dilayani. } \\
\text { b. } \quad \text { Nilai } 4 \text { = Rasio jalan rendah. } \\
\text { Yaitu luas jalan perkotaan } \\
\text { antara } 1 \mathrm{~s} / \mathrm{d} 2 \% \text { terhadap luas } \\
\text { wilayah yang dilayani. } \\
\text { Nilai } 3=\text { Rasio jalan rendah. } \\
\text { Yaitu luas jalan perkotaan } \\
\text { antara } 2 \text { s/d } 3 \% \text { terhadap luas } \\
\text { wilayah yang dilayani. } \\
\text { Nilai } 2=\text { Rasio jalan rendah. } \\
\text { Yaitu luas jalan perkotaan } \\
\text { antara } 3 \text { s/d } 5 \% \text { terhadap luas } \\
\text { wilayah yang dilayani. } \\
\text { Nilai } 1=\text { Rasio jalan rendah. } \\
\text { Yaitu luas jalan perkotaan }>5 \% \\
\text { terhadap luas wilayah yang } \\
\text { dilayani. }\end{array}$ \\
\hline $\begin{array}{l}\text { Pasokan } \\
\text { Air }\end{array}$ & $15 \%$ & $\begin{array}{l}\text { Nilai } 5=\text { diberikan kepada kawasan } \\
\text { yang berada diluar jarak } 10 \mathrm{~km} \text { dari } \\
\text { sumber air } \\
\text { 1. Nilai } 4=\text { diberikan kepada } \\
\text { kawasan yang berada pada jarak } \\
7.5 \mathrm{~s} / \mathrm{d} 10 \mathrm{~km} \text { dari sumber air } \\
\text { 2. Nilai } 3=\text { diberikan kepada } \\
\text { kawasan yang berada pada jarak } \\
5 \mathrm{~s} / \mathrm{d} 7.5 \mathrm{~km} \text { dari sumber air }\end{array}$ \\
\hline
\end{tabular}

\begin{tabular}{|c|c|c|}
\hline Variabel & Bobot & Tingkat klasifikasi dan penilaiannya \\
\hline & & $\begin{array}{l}\text { 3. Nilai } 2=\text { diberikan kepada } \\
\text { kawasan yang berada pada jarak } \\
2.5 \mathrm{~s} / \mathrm{d} 5 \mathrm{~km} \text { dari sumber air } \\
\text { 4. Nilai } 1=\text { diberikan kepada } \\
\text { kawasan yang berada pada jarak } \\
0 \mathrm{~s} / \mathrm{d} 2.5 \mathrm{~km} \text { dari sumber air }\end{array}$ \\
\hline
\end{tabular}

Sumber: Peraturan Menteri PU nomor 25/PRT/M/2009

[4] langkah yang dilakukan dalam penyelesaian masalah menggunakan metode Weighted Product adalah:

1. Normalisasi atau Perbaikan Bobot

$\mathrm{Wj}=\frac{W j}{\Sigma W j}$

Melakukan normalisasi atau perbaikan bobot untuk menghasilkan nilai $w j=1$ dimana $j=1,2, \ldots ., n$ adalah banyak alternatif dan $\Sigma$ wj adalah jumlah keseluruhan nilai bobot.

2. Menentukan nilai vektor (S)

$S_{i}=\prod_{j}^{n}=X_{i j} w_{j}$

Menentukan nilai vektor (S) dengan cara mengalikan seluruh kriteria dengan alternatif hasil normalisasi atau perbaikan bobot yang berpangkat positif untuk kriteria keuntungan (benefit) dan yang berpangkat negatif untuk kriteria biaya (cost). Dimana (S) merupakan preferensi kriteria, (X) merupakan nilai kriteria dan (n)merupakan banyaknya kriteria.

3. Menentukan Nilai Vektor (V)

$V_{i}=\frac{\prod_{j}^{n}=1 x_{i j} w_{j}}{\prod_{j}^{n}=1\left(x_{j}\right) w_{j}}$

Menentukan nilai vektor (V) dimana vektor merupakan preferensi alternatif yang akan digunakan untuk perangkingan dari masing masing jumlah nilai vektor $(\mathrm{S})$ dengan jumlah seluruh nilai vektor (S).

[7] nilai aspek dengan bobot maka didapatkan peringkat kerawanan kawasan, dalam hal ini akan dibagi dalam lima peringkat sebagai berikut :

1. Wilayah dengan nilai $0 \mathrm{~s} / \mathrm{d}$ 0,35dikategorikan sebagai wilayah yang aman

2. Wilayah dengan nilai $0,36 \mathrm{~s} / \mathrm{d}$ 0,51 dikategorikan sebagai wilayah yang agak aman

3. Wilayah dengan nilai $0,52 \mathrm{~s} / \mathrm{d}$ 0,67 dikategorikan sebagai wilayah agak rawan

4. Wilayah dengan nilai $0,68 \mathrm{~s} / \mathrm{d}$ 0,83 dikategorikan sebagai wilayah rawan

5. Wilayah dengan nilai $0,83 \mathrm{~s} / \mathrm{d} 1$ dikategorikan sebagai wilayah sangat rawan.

Jurnal J-ICOM (Jurnal Informatika dan Teknologi Komputer) Vol. 02 No. 01 (2021) 01 - 05 


\section{Hasil dan Pembahasan}

Dengan menggunakan langkah-langkah metode Weight Dari analisa perhitungan diatas memperlihatkan bahwa Product (WP) maka diperoleh hasil sebagai berikut :

Normalisasi atau Perbaikan Bobot sesuai persamaan (1) sebagai berikut

Tabel 2 Normalisasi Data

\begin{tabular}{|l|c|c|c|c|c|c|c|}
\hline \multirow{3}{*}{ Alternatif } & \multicolumn{7}{|c|}{ Kriteria } \\
\cline { 2 - 9 } & Nilai & Nilai & Nillai & Nilai & Nilai & Nilai & Nilai \\
\cline { 2 - 9 } & Pos & Kp & Rlkt & Hstr & Rj & Ark & P.Air \\
\hline PB. Blang Pase & 1 & 5 & 1 & 3 & 1 & 5 & 2 \\
\hline Mutia & 1 & 5 & 1 & 3 & 1 & 5 & 2 \\
\hline Daulat & 1 & 5 & 1 & 3 & 1 & 5 & 2 \\
\hline Peukan Langsa & 1 & 5 & 1 & 3 & 1 & 5 & 2 \\
\hline BlangSeunibong & 1 & 5 & 1 & 3 & 1 & 5 & 2 \\
\hline Blang & 1 & 5 & 1 & 3 & 1 & 5 & 2 \\
\hline AlueBeurawe & 1 & 5 & 1 & 3 & 4 & 5 & 4 \\
\hline Tualang Tengoh & 1 & 5 & 1 & 3 & 2 & 5 & 2 \\
\hline Jawa & 1 & 5 & 1 & 3 & 1 & 5 & 2 \\
\hline Teungon & 1 & 5 & 1 & 3 & 1 & 5 & 2 \\
\hline \multicolumn{1}{|c|}{ Bobot } & 0.2 & 0.05 & 0.15 & 0.15 & 0.15 & 0.15 & 0.15 \\
\hline
\end{tabular}

Menentukan nilai vektor (S) dan V sesuai persamaan (2) dan (3)

Tabel 3 Nilai S dan Nilai V

\begin{tabular}{|l|l|r|}
\hline Alternatif & Perhitungan S & Perhitungan V \\
\hline PB. Blang Pase & 0.553966257 & 0.103807 \\
\hline Mutia & 0.553966257 & 0.103807 \\
\hline Daulat & 0.553966257 & 0.103807 \\
\hline Peukan Langsa & 0.553966257 & 0.103807 \\
\hline Blang Seunibong & 0.553966257 & 0.103807 \\
\hline Blang & 0.553966257 & 0.103807 \\
\hline Alue Beurawe & 0.405527036 & 0.075991 \\
\hline Tualang Tengoh & 0.499262345 & 0.093556 \\
\hline Jawa & 0.5539666257 & 0.103807 \\
\hline Teungoh & 0.553966257 & 0.103807 \\
\hline
\end{tabular}

kecamatan langsa kota adalah kecamatan yang sangat rawan dikarenakan dari 10 gampong yang ada 8 diantaranya masuk kategori sangat rawan, 1 Gampong kategori rawan dan 1 gampong agak aman. Hal ini dikarenakan bahwa variable kepadatan penduduk (KP), histories kebakaran, dan jarak dengan pasokan air cukup besar sehingga nilai $S$ sangat tinggi. Sedangkan kecamatan langsa lama masuk zona daerah aman karena dari 14 gampong yang ada 3 gampong masuk kategori agak aman(range 0,36-51), 7 gampong masuk kategori agak rawan (range 0,52-0,67), 4 masuk kategori rawan $(0,68-0,83)$ dan tidak ada satupun yang masuk kategori sangat rawan. Hal ini dikarenakan wilayah langsa lama yang cukup luas dengan kepadatan penduduk yang belum begitu padat dan jangkauan pasokan air dekat dengan gampong lengkong. Sehingga dengan mengetahui daerah yang rentan potensi kebakaran bisa dijadikan ukuran dinas terkait untuk lebih siaga terhadap daerah yang masuk kategori rawan dan sangat rawan

\section{Ucapan Terimakasih}

$-$

\section{Daftar Rujukan}

[1] Firmansyah, 2016. Analisis Resiko Bencana Kebakaran Di Kota Bukit Tinggi. Infomatek ISSN: 1411 - 0865 vol 18 Nomor 2. Fakultas Teknik universitas pasundan

[2] Jawad, A. dkk 2015. Zonasi Daerah Rawan Kebakaran Hutan Dan Lahan Di Kabupaten Kubu Raya Provinsi Kalimantan Barat. Jurnal Hutan Lestari. Vol. 3 (1).

[3] Jati, S.K, 2013. perancangan letak hidran kebakaran pada jaringan distribusi sistem penyediaan air minum (studi kasus: kecamatan sayung, kabupaten demak). Prodi Teknik lingkungan fakultan Teknik universitas Diponogoro

[4] Kusumadewi, Hartati, Harjoko dan Wardoyo, 2006. Fuzzy MultiAttribute Decision Making (Fuzzy MADM). Yogyakarta: Graha Ilmu

[5] Keputusan Menteri Negara Pekerjaan Umum nomor : 11/KPTS/2000 tentang Ketentuan Teknis Manajemen Penanggulanagan Kebakaran di Perkotaan

[6] Peraturan Kepala Badan Nasional Penanggulangan Bencana Nomor 2 Tahun 2012 tentang Pedoman Umum Pengkajian Risiko Bencana, (2012).

[7] Peraturan Menteri Pekerjaan Umum Nomor 20 Tahun 2009 Pedoman Teknis Manajemen Proteksi Kebakaran Di Perkotaan. Jakarta.

[8] Qonun Kota Langsa nomor 12 tahun 2013 tentang rencana Tata Ruang Wilayah Kota tahun 2012-2032

[9] Rencana Induk Sistem Pencegahan Kebakaran Kota Langsa 2018

\section{Kesimpulan}

Jurnal J-ICOM (Jurnal Informatika dan Teknologi Komputer) Vol. 02 No. 01 (2021) 01 - 05 
Heri Irawan, Faiz Isma, Irwansyah

Jurnal J-COM (Jurnal Informatika dan Teknologi Komputer) Vol. 02 No. 01 (2021) 01 - 05

[10] Saraswati, Dinimiar Fitrah, 2017. Analisis Daerah Resiko [11] Sudiana, nana dkk, 2018. Urban fir Hazard Analysis of DKI bencana kebakaran dikota Surabaya mengunakan system SIG. Jakarta Province, Jurnal Sains dan Teknologi Mitigasi Bencana, Vol. JURNAL TEKNIK ITS Vol. 6, No. 2 (2017), 2337-3520

13, No. 2, Desember 2018 
